\title{
Inserção social como categoria de análise socioeconômica: um estudo sobre administração pública e o setor imobiliário de Florianópolis
}

\author{
Enio Luiz Spaniol \\ Universidade do Estado de Santa Catarina \\ Ivoneti Ramos \\ Universidade do Estado de Santa Catarina \\ Samantha Buglione \\ Universidade do Estado de Santa Catarina \\ Deisiane Delfino \\ Universidade do Estado de Santa Catarina \\ Maria Eduarda Razerra \\ Universidade do Estado de Santa Catarina
}

\begin{abstract}
A gestão urbana é um dos temas que vem desafiando a administração pública. Este artigo analisa a gestão urbana e a administração pública a partir do mercado imobiliário e das inserções sociais que influencia(ra)m o crescimento da cidade. A tese central do estudo é que o paradigma da racionalidade econômica não é suficiente para absorver a diversidade de variáveis presentes em um campo como o do setor imobiliário. Assim, parte-se do pressuposto de que o estudo de um campo a partir das inserções sociais é uma forma eficiente de conhecer as representações sociais e seu impacto. Isso porque o setor imobiliário representa uma diversidade de conflitos que acabam por influenciar as políticas públicas. Entre os resultados alcançados destacam-se o mapeamento de Florianópolis em núcleos de desenvolvimento do setor imobiliário e a identificação inicial das inserções sociais preponderantes em cada um destes núcleos, bem como uma interpretação sobre o significado e o papel analítico das inserções sociais. Conclui-se que a nova sociologia econômica é o marco teórico mais adequado para o estudo de campos complexos e que, entre as inserções sociais, é preciso incluir uma nova categoria denominada inserção ambiental.
\end{abstract}

Palavras-chave: nova sociologia econômica; racionalidade econômica; inserção social.

Artigo recebido em 30 maio 2012 e aceito em 16 abr. 2013. 
Inserciones sociales como una categoria de análisis socioeconomica: um estúdio de la administración pública y de ló mercado immobiliario de Florianópolis

La gestión urbana es uno de los temas que viene desafiando a la administración pública. En éste artículo se analiza la gestión urbana y la administración pública desde el mercado inmobiliario y de las inserciones sociales que influyen e influenciaron el crecimiento de la cuidad. La tesis central del estudio es que el paradigma de la racionalidad económica no es suficiente para absorber la diversidad de variables presentes en un área como la del sector inmobiliario, con lo que parte del supuesto de que el estudio de un campo de las inserciones sociales es una manera eficaz de conocer las representaciones sociales y su impacto. Eso es porque el sector inmobiliario representa una variedad de conflictos que en última instancia influyen en las políticas públicas. Entre los logros se destacan, el mapeamiento de Florianópolis en núcleos de desarrollo del sector inmobiliario y la identificación inicial de las inserciones sociales preponderantes en cada uno de estos núcleos, así como una interpretación del significado y el papel de las inserciones sociales. La conclusión de que la nueva sociología económica es el marco teórico más apropiado para el estudio de campos complejos y que entre las inserciones sociales, es necesario incluir una nueva categoría denominada incerción ambiental.

Palabras clave: nueva sociología económica; racionalidad económica; inserción social.

Social insertions as a category of socio-economic analysis: a study of public administration and real state in Florianópolis

Urban management is one of the themes that has been challenging the public administration. This article analyzes the urban management and public administration from the real state market and social insertions that influences the city growth. The central thesis of the study is that the paradigm of economic rationality is not sufficient to absorb the diversity of variables present in a field such as real state, thus starts from the assumption that the study of a field from the social insertions is an efficient way to understand the social representations and their impact. That's because the real state sector represents a variety of conflicts that ultimately influence public policy. Among the achievements stands out cataloging Florianopolis in cores of real state development and initial identification of prevalent social insertions in each of these nucleus, as well as an interpretation of the meaning and role of analytical social background. The conclusion is that the new economic sociology is the most appropriate theoretical framework for the study of complex fields and that, among the social insertions, you need to include a new category called environmental insertion.

KEYWORDs: new economic sociology; economic racionality; social insertion.

\section{Introdução}

É possível compreender a administração pública a partir de várias perspectivas. Entre os consensos possíveis pode-se destacar a ideia de que este é um campo que trata do conjunto de atividades diretamente destinadas à execução de tarefas cruciais para efetivação do interesse público. Nessa linha, a gestão urbana vem desafiando as ações e áreas que tratam do interesse público, logo, da administração pública. Como parte do campo da gestão urbana, o setor imobiliário movimenta interesses diversos e sua análise representa uma oportunidade de compreender como os comportamentos de natureza econômica moldam não apenas as 
políticas públicas, mas os próprios espaços urbanos; e assim também como as políticas públicas urbanas auxiliam na formatação dos comportamentos humanos no campo econômico. Tornam-se, desse modo, fatos sociais, no sentido trabalhado em Durkheim (1893). Este artigo utiliza as inserções sociais como fio condutor para analisar a gestão urbana de Florianópolis e a consequente influência do mercado imobiliário neste processo. A análise considera que — independentemente dos fatores subjetivos que levaram a um maior ou menor crescimento de determinada inserção, por exemplo, a construção de um shopping ou alteração do Plano Diretor - essas inserções sempre serão sintomáticas de interesses e conflitos sociais tornando-se, assim, elas mesmas, um fato social. O estudo, portanto, tem como objeto as inserções como variáveis e não os fatores subjetivos dos membros da comunidade analisada. Em outras palavras, parte-se de um postulado de que as inserções são expressões de subjetividades. O critério para esta escolha está no sentido de representação social de Durkheim (Pinheiro Filho, 2004). Durkheim considera que a sociedade é mais que a soma de indivíduos vivos e que os fatos sociais são formados pelas representações coletivas. Isto é, seus mitos, crenças morais, os elementos que explicam como a sociedade vê a si mesma e o mundo que a rodeia. Um maior avanço de determinada inserção social é uma variável que permite identificar os valores predominantes ou de maior poder na cidade de Florianópolis. Torna-se, portanto, uma forma indireta de analisar a cultura local. As inserções sociais são uma forma de observar como os fatos sociais, na área econômica, também são moldados pelas políticas públicas e pelos espaços urbanos.

Para desenvolver esta análise, o presente estudo tem como objeto o mercado imobiliário da cidade de Florianópolis e as inserções sociais que influencia(ra)m em seu crescimento.

Neste estudo se evidenciam as inserções sociais presentes ao longo dos ciclos históricos do setor imobiliário de Florianópolis. Nas regiões onde o processo de urbanização ocorre, além da transformação do espaço e da nova estruturação com recursos públicos em prol dos investimentos feitos, existem impactos sociais à população local. Um dos impactos é o aumento do custo de vida nas várias regiões alteradas da cidade. Isto estimula tanto a mudança da população local para outras regiões quanto o estabelecimento de novos tipos de serviços a fim de atender o novo formato da localidade.

A tese central é de que o paradigma das escolhas racionais não é suficiente para absorver a diversidade de variáveis presentes em um campo como o do setor imobiliário. Como em um contraponto, este estudo opta pela nova sociologia econômica como pano de fundo para pensar a análise proposta. Isso por considerar a possibilidade de observar um maior número de variáveis que influenciam no crescimento deste setor.

A nova sociologia econômica (NSE) surgiu resgatando importantes autores clássicos como Marx, Durkheim, Weber, Simmel, Veblen, Pareto (Minella et al., 2005). A partir de suas análises, a NSE permitiu novos olhares sobre os fenômenos econômicos ampliando a forma de definir "fato" ou "ato" econômico, bem como elaborando uma metodologia e conceitos apropriados para analisar tais fatos ou atos. Ao analisar sociologicamente o núcleo da ciência econômica, ou seja, os mercados, a sociologia econômica permitiu descortinar o papel regulatório e as relações de poder inerentes ao campo. O mercado é visto, conforme observa Bourdieu 
(1997), como uma construção social. Nesse sentido, reafirma-se a tese original deste estudo, ou seja, de que o paradigma econômico das escolhas racionais não possui as ferramentas suficientes para a análise de campos complexos como o do sistema imobiliário, principalmente no que se refere ao seu impacto e ao seu significado como fato social.

Primeiramente, contesta-se o modelo econômico: a economia clássica, para a qual o agente econômico tem caráter preponderantemente estático. Pareto, Durkheim e Weber (Steiner, 2006) entendem a economia complexa com imbricações entre os comportamentos econômicos e os baseados em normas sociais, constituídas a partir de representações e instituições, e compreendem que há complementaridade entre a economia e a sociologia. A sociologia econômica recebeu impulso importante com a obra A grande transformação de Polanyi (2000 [1944]), com a argumentação de que há "enraizamento" entre economia e relações sociais. A nova sociologia econômica aparece de forma mais vigorosa no fim dos anos 1970. Granovetter (1985) expõe duas concepções: 1 ) a ação econômica é socialmente localizada e não pode ser explicada, apenas, por motivos individuais; ${ }^{1}$ 2) as instituições sociais não brotam automaticamente, elas são construídas socialmente. O referido autor, para se contrapor à visão de que a economia estaria deslocada das relações sociais na modernidade, propõe o problema da incrustação, com "o argumento de que os comportamentos e as instituições a serem analisadas são tão compelidos pelas contínuas relações sociais que interpretá-las como sendo elementos independentes representa um grave mal entendido" (Granovetter, 1985:33). Na mesma linha, Zukin e DiMaggio (1990) e Fligstein (2001) adotam o conceito de "inserção" para sustentar a ideia de que há uma profunda imbricação entre relações econômicas de mercado e relações sociais. A NSE tira, pois, as relações sociais de seu espaço marginal e as coloca como constituidoras do mercado, valendo-se, para tanto, inclusive dos conhecimentos da área econômica.

Por haver vários autores que expõem posições diferentes para caracterizar a NSE, neste artigo se adotará o conceito de "inserção", a partir da tradução de embeddedness (transcrita por alguns como incrustação ou também imersão) de Granovetter (1985), cuja expressão, depois, foi adotada mais explicitamente, inicialmente por Zukin e DiMaggio (1990), e, posteriormente, por Fligstein (2001). A ideia central, em síntese, é a de que os comportamentos e as instituições são compelidos pelas relações sociais. As quatro formas de "inserção" social na economia, que têm sua formulação em Zukin e DiMaggio (1990), são aqui assumidas como: inserção estrutural, política, cultural e cognitiva.

A fim de observar a tese da NSE este estudo aplica as inserções sociais no campo social do setor imobiliário, especificamente na cidade de Florianópolis. O setor imobiliário de Florianópolis é a metáfora possível que serve como laboratório para a criação de uma metodologia de análise ora apresentada. Destaca-se, inicialmente, que nos locais de incidência da urbanização ocorre: a) transformação do espaço e da nova estruturação com recursos públicos em prol dos investimentos feitos; b) impactos sociais à população local, tal como o aumento

\footnotetext{
${ }^{1}$ As inserções sociais como objeto de análise são uma tentativa de estudar a ação econômica para além de motivos individuais ou subjetivos, mas como fatos sociais.
} 
do custo de vida nas várias regiões alteradas da cidade, que estimula a população local a se mudar para outras regiões mais afastadas; c) abertura de uma série de estabelecimentos para atender as necessidades da nova população; e ainda, d) modificações das paisagens e realidades sociais motivadas pela força do capital, agindo na diferenciação cultural, bem como na perda de uma identidade regional com a saída da população local e entrada de uma majoritária população não originária da ilha de Florianópolis. Esses dados corroboram a afirmação de que a ação econômica do setor imobiliário de Florianópolis é de extrema complexidade, sendo este um campo propício para identificar, a partir das inserções sociais, as motivações e interesses individuais e coletivos.

\section{Aspectos teóricos: da economia clássica à nova sociologia econômica (NSE)}

O pensamento clássico, que se desenvolveu durante a segunda metade do século XVIII e no século XIX, apresenta questões em torno das transformações do processo produtivo geradas pela Revolução Industrial. Adam Smith, com A riqueza das nações, altera a noção de riqueza afirmando que não são a prata e o ouro que determinam o nível de riqueza de uma nação, e sim a capacidade produtiva humana. Ou seja, qualquer transformação que aprimore a capacidade produtiva está gerando enriquecimento para uma nação. As ideias gerais dos clássicos defendiam o liberalismo, apoiando-se no conceito de racionalidade econômica, uma busca competitiva do bem-estar individual.

No livro Teoria dos sentimentos morais, publicado em 1759, a ideia fundamental sobre o desenvolvimento de os sistemas éticos se desenvolverem por meio de um processo natural, a partir das relações pessoais individuais, evidencia a hipótese de que o indivíduo decide sobre suas ações a partir do comportamento da sociedade. Smith defendia "um 'sistema de liberdade natural' no qual todos seriam livres para perseguir e alcançar seus próprios interesses" (Fusfeld, 2003:41). Essa tese possibilitou, posteriormente, o desenvolvimento da ordem social em uma sociedade individualista.

Ricardo (1988), considerado o legítimo sucessor de Adam Smith, acreditava que as políticas econômicas deveriam agir de maneira a promover a acumulação de capital, pois este era a maior fonte de expansão da economia. De acordo com Fusfeld (2003:58), Ricardo acreditava que "a liberdade econômica proporcionava lucros máximos, que os lucros eram a fonte de capital de investimento e que a economia competitiva incentivava os investimentos maximizadores dos lucros".

$\mathrm{Na}$ continuidade do processo capitalista com a expansão das atividades comerciais, industriais e mais recentemente dos serviços, o enfoque privilegiado dado pelos economistas, na busca de identificação das causas comportamentais humanas, tem sido exatamente o fator econômico (necessidades básicas, interesses etc.). A sociologia considera importantes as contribuições da economia clássica e neoclássica, mas aponta para equívocos, só possíveis de serem percebidos por análises críticas de contemporâneos, como Durkheim, Weber e Pareto 
da sociologia antiga. Esses autores introduziram os aspectos sociopolíticos e culturais como coparticipantes na formulação de hábitos de comportamento. A nova sociologia econômica aprofunda esta postura crítica em relação à economia clássica estabelecendo o princípio de o mercado ser uma construção social. E este passa a ser o contraponto da economia clássica.

Embora esta pesquisa reconheça que a nova sociologia econômica expresse seu contraponto diretamente com os economistas neoclássicos e com a teoria das escolhas racionais, para fins deste artigo, o debate iniciará no pensamento econômico clássico, porque foi com Adam Smith que a economia passou a ser pensada de forma mais sistemática e baseada em alguma noção de racionalidade. Mesmo que pontualmente a NSE baseie sua crítica à neoclássica, a NSE é a negação do tradicionalismo econômico. E essa negação não é somente da racionalidade nas escolhas, mas também do fato de que a economia explica os fenômenos sociais a partir do comportamento individual, restringindo-se a fatores econômicos. Este posicionamento é abordado por John Stuart Mill, um dos expoentes da economia clássica.

A NSE pode se materializar na sociologia do mercado e constitui-se em uma ferramenta de análise para melhor compreender a complexa relação de mercado, na qual está inserido o setor imobiliário. Desde a virada do século XIX para o século XX as posições de Pareto, Durkheim e Weber (Steiner, 2006) defendem que há imbricações sociais na constituição da ordem econômica. Pareto (1981) afirma ser a economia mais complexa e dinâmica do que pressupõe o homo economicus. Advoga ser necessário aproximar a economia pura (abstrata) da economia aplicada (o homo economicus têm paixões) e da sociologia (dimensões da vida social: religiosa, política, militar, sexual...). Durkheim (1893) diz que há imbricação entre os comportamentos egoístas e os baseados em normas sociais, entendendo o fato econômico como um fato social, ou seja, a economia também estaria caracterizada como maneira de agir, pensar e sentir, externas aos indivíduos, mas possuidora de um poder de coerção sobre eles. Para Weber (1970), o específico no estudo do social (inclusive a motivação da ação econômica) reside na existência de ações individuais às quais confere sentido e também leva em conta ações de outros indivíduos. O autor diz que há complementaridade entre a economia e a sociologia econômica que procura as relações sociais nas quais está expresso o comportamento egoísta.

Polanyi (2000) faz uma clivagem sucumbindo diante da argumentação dos economistas clássicos de que nas sociedades modernas o mercado é autônomo e não depende das normas e dos valores sociais. A nova sociologia econômica, com Granovetter (2003), critica esta clivagem no tempo introduzida por Polanyi. Sustenta que o comportamento econômico encontra-se incrustado nas relações sociais em qualquer fase, época ou modelo econômico. Alinhando a sua posição, Granovetter procura estabelecer um equilíbrio entre as concepções subsocializadas (frágil presença de relações sociais na economia) e as sobressocializadas (definição da ordem econômica quase com exclusividade pela educação, valores morais e normas legais). Fligstein (2001) assume a concepção do mercado como política e, junto com Zukin e DiMaggio (1990), percebe a economia imersa na sociedade. Ou seja, a NSE registra a postura de que há quatro inserções sociais básicas na economia: a estrutural, a política, a cultural e a cognitiva. 
Portanto, da Antiga para a NSE, a partir da década de 1970, a análise dos aspectos sociais, sobremaneira pela presença do Estado no campo econômico, passa a ser necessária para compreender a construção da ordem econômica. Desta perspectiva, Granovetter (2003) sugere que todos os processos de mercado, incluindo o imobiliário, são passíveis de análise sociológica, cujas avaliações revelam elementos centrais e não periféricos dos mesmos processos. Quando se refere a indivíduos atomizados e a objetivos econômicos, a teoria das escolhas racionais é inconsistente com a perspectiva da incrustação. Granovetter (2003) faz a crítica de que os economistas normalmente analisam comportamentos motivados apenas por interesses, puramente econômicos, e as outras motivações, como sociabilidade, aprovação, status e poder, encontram-se em outras esferas. Dentro da lógica da NSE, é central constatar a existência de instituições criadas no relacionamento social para orientar o mercado. Para os agentes reguladores, nesta nova relação, a sociologia econômica analisa o contexto cultural no qual um grupo está inserido. Portanto, considera que as redes sociais e os ambientes culturais, nos quais estão inseridas as pessoas, influenciam nas variações de mercado. A crítica necessária, na concepção dos culturalistas, é de que a cultura (por exemplo, a dificuldade de economistas em lidar com a formação dos gostos, moldados por relações sociais e atributos simbólicos) está ausente da maior parte da teoria econômica; eis que o homo economicus é visto como universal.

Desta forma, a NSE não aceita as concepções da economia clássica de que o comportamento humano é definido na economia e de que as relações sociais têm papel marginal. A NSE tenta provar que a economia está na sociedade e não o seu inverso.

Sumarizando, o conjunto de enfoques para analisar a economia sob um prisma sociológico é amplo: enraizamento, incrustação, construção social do mercado, inserções estruturais, políticas, cognitivas e culturais. A NSE oferece, portanto, subsídios para a realização de uma análise mais cuidadosa da vida econômica e social, portanto, da ação econômica e dos fatos sociais. Por esta razão, assume-se a postura de crítica à economia clássica e neoclássica e a consequente adesão às múltiplas e variadas interpretações que são adicionadas pela NSE, a qual incorpora elementos estruturais, sociais, culturais e cognitivos para melhor compreender a dinâmica relação do mercado imobiliário de Florianópolis.

\subsection{Refinando as inserções sociais}

Este estudo permite observar as conexões entre economia e sociedade a partir do setor imobiliário de Florianópolis. Para chegar a essa conclusão parte-se do conceito de "inserção" de Zukin e DiMaggio (1990) e Fligstein (2001). A ideia central é usar as inserções como ferramentas para analisar o setor imobiliário. Cabe observar que o termo "inserção" é adotado com o significado de interconexão, interpenetração ou imbricação entre economia e sociedade. Em um primeiro momento do estudo sistematizaram-se as inserções a partir de caracterizações e exemplos, conforme quadro abaixo: 
Quadro 1

Inserções sociais e respectivas características

\begin{tabular}{|c|c|}
\hline $\begin{array}{l}\text { Inserção } \\
\text { Social }\end{array}$ & Característica \\
\hline Política & $\begin{array}{l}\text { Elaboração e/ou alteração na legislação / Plano diretor } \\
\text { Alvarás / Ações judiciais / Normas de regulamentação do solo / Políticas públicas / Organização da } \\
\text { sociedade civil }\end{array}$ \\
\hline Estrutural & $\begin{array}{l}\text { Construção de obras públicas: aterros, avenidas, rodovias / Escolas, universidades e institutos de pesquisa } \\
\text { / Serviços: órgãos públicos, aeroporto, rodoviária, postos de polícia, postos de saúde, hospitais / Consumo: } \\
\text { mercados, shoppings, feiras }\end{array}$ \\
\hline Cultural & $\begin{array}{l}\text { Regiões históricas e tradicionais da cidade / Teatros e cinema / Polos de turismo / Parques / Locais para } \\
\text { prática de esporte / Bares, restaurantes, casas noturnas / Status }\end{array}$ \\
\hline Cognitiva & $\begin{array}{l}\text { City marketing / Qualidade técnica da construção / Histórico da construtora e credibilidade / Conforto, } \\
\text { comodidade, praticidade, seguranças internas e externas ao imóvel / Construção sustentável / Recursos } \\
\text { naturais: relevo, hidrografia, vegetação e paisagem }\end{array}$ \\
\hline
\end{tabular}

Fonte: Elaborado pelos autores com base em Zukin e DiMaggio (1990), Fligstein (2001) e na pesquisa realizada.

A partir desse quadro e do exercício empírico de observar as inserções em um campo de análise específico, no caso, o distrito-sede de Florianópolis, desenvolveu-se, com uso do método dialético-indutivo, uma conceituação para cada inserção a fim de viabilizar a criação de categorias científicas de análise. Preliminarmente é preciso ter em conta que um conceito é uma representação mental com função classificatória (Audi, 2006). Diferentemente de caracterizações e exemplos, que são contingentes, um conceito se presta à universalidade e é uma definição sobre algo. Em outras palavras, é uma ideia sobre a "coisa em si", ou o que é possível observar dela, mesmo que seja apenas uma representação.

Tanto Zukin e DiMaggio (1990) quanto Fligstein (2001) definem o que é uma inserção, mas não desenvolvem um conceito para os tipos de inserções que fizeram referência. A partir do campo do sistema imobiliário realizamos definições sobre cada inserção.

\subsubsection{Inserção política}

A inserção política é a forma como se visualizam, nos espaços urbanos, os elementos políticos de uma cidade, é o polis (politikós), que significa tudo o que se refere à cidade (Bobbio, Matteuci e Pasquino, 2000). Especificamente as questões de ordem pública que permitem, dentro da diversidade, uma linguagem comum. Refere-se, portanto, aos acordos estabelecidos por membros de uma comunidade moral de forma a permitir que esses membros tenham condições de viver conforme suas crenças morais (Buglione, 2010). A 
política - como inserção - é o resultado dos conflitos de interesses, dos arranjos e acordos sociais, sejam eles éticos ou não, mas que, ao final, irão criar regras cuja incidência será sobre todos os que vivem em determinado território. Em outras palavras, política será tudo aquilo que diz respeito a todos, não porque seja expressão do interesse público ou do bem ou mesmo do justo, mas porque tem um efeito vinculante sobre os membros de um determinado grupo social. Utiliza-se a categoria política como forma para nominar o que acaba se constituindo como o campo de gerenciamento dos membros de uma comunidade moral. A política é observada, assim, como um dos mecanismos para os que governam (archein do grego), bem como para os que conduzem ou gerenciam (agere do latim) um grupo de pessoas em determinado locus. É, em síntese, o exercício de um poder exclusivo sobre um determinado território com efeito sobre todos (erga omnes) (Bobbio, Matteuci e Pasquino, 2000).

\subsubsection{Inserção estrutural}

Estrutura é a "disposição e ordem das partes dum todo" (Cunha, 2000). Trata-se, portanto, de tudo que dá forma a um determinado espaço. Na lógica de cidades, a estrutura será o que ordena o rol de direitos e deveres dos membros de uma cidade, estando, assim, vinculada às disposições políticas. Em outras palavras, não é possível ordenar algum espaço sem antes haver um permissivo - ou o dever — previamente acordado para tanto. Pode-se dizer, assim, que a inserção estrutural é a viabilidade, a materialização, dos acordos legítimos, sejam eles éticos ou não, de um determinado grupo social. A estrutura estará direta e indiretamente vinculada ao Estado. Diretamente porque se refere aos serviços públicos e aos mecanismos de garantia de direitos cuja responsabilidade é do Estado, como saneamento, pontes, hospitais, postos de saúde; e indiretamente porque são os espaços reservados para o livre exercício dos interesses dos particulares, como comércio, feiras, mercados.

\subsubsection{Inserção cultural}

Etimologicamente cultura está relacionada a cultus, do latim: que é o que determinado grupo social valoriza e cultiva (Cunha, 2000); é um éthos. A “inserção cultural”, portanto, é o que dá significado para o grupo social em análise. Por dar significado, é um campo de normatização moral das relações sociais. Em Florianópolis, no distrito sede, por exemplo, é possível encontrar um Curiódromo, o que evidencia algo muito particular da cultura e, ainda, um permissivo social valorizado. Este trabalho não faz uma distinção entre o que poderia ser chamado de "cultura elevada", "cultura política" ou "cultura de massa", apenas inclui na inserção tudo que possa ser observado como algo de valor para o grupo social, especificamente os elementos, hábitos valorizados e cultivados. Dessa forma, fazem parte da inserção cultural elementos 
bastante diversos, como uma pista de skate, um curiódromo, uma Igreja, um clube social, ou mesmo uma região histórica ou com status social diferenciado.

\subsubsection{Inserção cognitiva}

A cognição, cognitio do latim, é a aquisição de um conhecimento (Cunha, 2000). É o que permite, pelo saber, perceber, observar, analisar determinado objeto. Ou, paradoxalmente, pelo uso confuso e assimétrico de determinado fato confundir a compreensão. Em relação ao mercado, algumas atividades criam novas concepções sobre o mundo que evoluem de forma a tornarem-se fatos sociais. Quando as antigas casas de pescadores, construídas com as costas para o mar, foram sendo substituídas por prédios, cuja valorização estava exatamente na vista para o mar, percebe-se, aí, uma intervenção que altera a cultura local. Esse fenômeno é observado no aterro que deu origem à avenida Beira-Mar Norte em Florianópolis. Nesse exemplo, a atividade econômica promove uma nova forma de compreensão das relações alterando a estética da cidade e o comportamento dos moradores. Steiner (2006) explica esse processo observando que há uma economia que é saber e outra que é atividade. Com isso, "a economia (saber) tem uma influência sobre a economia (prática) na medida em que ela fornece discursos que legitimam a atividade econômica (...) e na medida em que ela se impõe, cada vez mais, como uma dimensão essencial do político, o que Frédéric Lebaron (2000) chama de "crença econômica"' (Steiner, 2006:108). Além do impacto da atividade do mercado sobre as relações sociais, no que se refere às mudanças de percepção sobre o mundo, Steiner (2006) afirma que o conhecimento econômico, em si, influencia as relações sociais. Nesse sentido, a defesa da relação entre a dimensão cognitiva e econômica é defendida pelo autor. A dimensão cognitiva, portanto, não se reduz a informação e conhecimento, mas "aos valores por meio dos quais os indivíduos concebem o mundo, e agem em consonância com isso" (Steiner, 2006:118). Por isso, pode-se afirmar que a inserção cognitiva, de certa forma, está presente em todas as outras inserções, assim como todas as inserções têm uma estreita e mútua interconexão.

\subsubsection{Inserção ambiental}

Apesar de o meio ambiente não ser uma inserção, no sentido de resultado de uma ação humana, torna-se inserção porque é algo que passa a fazer parte das relações humanas. A inserção ambiental não foi proposta por Zukin e DiMaggio (1990) e nem por Fligstein (2001), mas ela está sendo proposta no presente artigo como uma nova inserção social. Esta inovação parte do pressuposto de que, ao se permitir o uso ou exigir a preservação de algum bioma, se altera, em grupos sociais, o valor reconhecido daquele ecossistema específico. A inserção ambiental, refere-se, portanto, aos recursos naturais existentes em um determinado local, preservados ou recuperados. É o que estava originalmente em determinado território e que tem valor instru- 
mental ou intrínseco. É uma estrutura que não foi criada pela ação humana, mas passa a fazer parte do rol de importâncias de um grupo social.

\section{Aspectos metodológicos}

Entre os desafios deste estudo está o processo criativo de verificação das inserções em um território específico de forma a criar uma metodologia capaz de ser replicada por outros grupos. Trata-se, em outros termos, de verificar em que medida é possível utilizar as inserções como categorias de análise. Os autores elegeram como estudo piloto o distrito sede da cidade de Florianópolis. A partir disso, criaram alguns critérios para desenvolver o mapeamento.

Foram dois métodos utilizados: a dialética-empírica e o inter-rater reliability (Armstrong, 1997). Ambos permitem a padronização de dados a partir da troca de informações a fim de obter um material coeso e capaz de se constituir como referência. Em um primeiro momento, o mapeamento das inserções no distrito sede ocorreu com informações de senso comum, obtidas por meio de uma oficina com um grupo focal constituído por acadêmicos do curso de Administração Pública da Esag da Universidade do Estado de Santa Catarina (Udesc).

O primeiro critério, portanto, foi o de aplicar as inserções no mapa a partir de dados ordinários, ou seja, do senso comum. Com esses dados em mãos realizou-se a verificação das inserções e sua conceituação fazendo uso do método dialético-indutivo. O segundo estágio do mapeamento foi a correção das inserções no mapa a partir dos conceitos desenvolvidos pelos autores. Por fim, o terceiro estágio de mapeamento: sua verificação e validação através do inter-rater reliability. A validação das informações ocorreu a partir da seleção de alguns interlocutores habilitados para analisarem os dados iniciais revisados.

As pessoas escolhidas deveriam conjugar alguns dos critérios: a) terem nascido e crescido na cidade, b) trabalharem no setor imobiliário ou com planejamento urbano e c) terem estudos e pesquisas na área. O mapa apresentado é resultado, em síntese, das seguintes etapas: 1. aplicação das inserções no território a partir do primeiro quadro feito pelos autores (quadro 1); 2. construção dos conceitos e revisão da tabela, método dialético-indutivo; 3. correção do mapeamento das inserções no mapa do distrito sede tendo como referência o quadro 3 revisado pelos autores; e 4. verificação e validação das inserções, método inter-rater reliability.

Destaca-se que o processo precisou seguir esse caminho porque a conceituação das inserções pressupunha a análise de dois fatores: um empírico e outro teórico. Foi, portanto, o resultado da análise desse processo (dialética) que permitiu aos autores obterem os elementos necessários para compor o conceito de cada inserção social.

Como um dos resultados da metodologia utilizada apresenta-se o quadro de sistematização abaixo: 
Quadro 2

Conceitos e características das inserções sociais ${ }^{2}$

\begin{tabular}{|c|c|c|}
\hline Inserção Social & Conceito - Síntese & Característica \\
\hline Política & $\begin{array}{l}\text { São os acordos estabelecidos por membros } \\
\text { de uma comunidade moral com efeito erga } \\
\text { omnes e, por essa razão, passar a governam as } \\
\text { suas práticas. }\end{array}$ & $\begin{array}{c}\text { elaboração e/ou alteração na legislação / plano } \\
\text { diretor } \\
\text { alvarás / ações judiciais / normas de } \\
\text { regulamentação do solo / políticas públicas / } \\
\text { organização da sociedade civil }\end{array}$ \\
\hline Estrutural & $\begin{array}{l}\text { É tudo que dá forma a um determinado espaço } \\
\text { tendo como referência o rol de direitos e } \\
\text { deveres dos membros de uma cidade, estando, } \\
\text { assim, vinculada às disposições políticas. }\end{array}$ & $\begin{array}{l}\text { construção de obras públicas: aterros, avenidas, } \\
\text { rodovias / escolas, universidades e institutos de } \\
\text { pesquisa / serviços: órgãos públicos, aeroporto, } \\
\text { rodoviária, postos de polícia, postos de saúde, } \\
\text { hospitais / consumo: mercados, shoppings, } \\
\text { feiras, bares, restaurantes, conforto, comodidade, } \\
\text { praticidade, segurança interna e externa, } \\
\text { sustentabilidade da construção }\end{array}$ \\
\hline Cultural & $\begin{array}{l}\text { É o que dá significado a um grupo social a partir } \\
\text { de suas crenças, hábitos e tradições e, por essa } \\
\text { razão, promove um regramento moral e um } \\
\text { escalonamento valorativo das práticas sociais. }\end{array}$ & $\begin{array}{l}\text { regiões históricas e tradicionais da cidade / } \\
\text { teatros e cinema / polos de turismo / parques / } \\
\text { locais para prática de esporte / casas noturnas / } \\
\text { city marketing / qualidade técnica da construtora } \\
\text { / histórico e credibilidade da construtora }\end{array}$ \\
\hline Ambiental & $\begin{array}{l}\text { São os recursos naturais (ecossistemas } \\
\text { naturais) originais, preservados ou recuperados, } \\
\text { existentes em um determinado território. }\end{array}$ & $\begin{array}{l}\text { recursos naturais: mares, mangue, rios, } \\
\text { morros, dunas, flora, fauna, nascentes (...) }\end{array}$ \\
\hline
\end{tabular}

Fonte: Elaborado pelos autores com base na pesquisa realizada.

A partir destes procedimentos metodológicos estruturou-se a análise posterior sobre o setor imobiliário em Florianópolis.

\section{0 setor imobiliário em Florianópolis}

Florianópolis é a capital e a segunda maior cidade do estado de Santa Catarina com 421.440 habitantes; está localizada na faixa litorânea central do estado e possui $671,5 \mathrm{~km}^{2}$ de território, compreendido por $97 \%$ de área insular e 3\% de área continental (IBGE, 2010). A população total de Florianópolis na década de 1950 era de 48.264 habitantes e cresceu 187\% entre

\footnotetext{
${ }^{2}$ Conforme o que foi abordado no item 2.1.4 deste artigo, este quadro síntese integrou, diluiu, a inserção cognitiva nas demais inserções.
} 
as décadas de 1960 e 1970 . O aumento populacional entre as décadas de 1970 e 1990 foi de 85\% e entre 1990 e 2010, de 65\%. Em 2000, o município de Florianópolis apareceu com um dos melhores Índices de Desenvolvimento Humano (IDHs) do Brasil, sendo o quarto colocado, com 0.875, no IDH dos municípios do Brasil (PNUD, 2011).

A cidade está entre as 20 cidades mais visitadas do Brasil por estrangeiros e uma das três cidades mais visitadas do país desde o ano 2000. Conforme a Associação Brasileira de Agências de Viagens (DC, 2011) e o estudo "Demanda turística internacional" elaborado pelo Ministério do Turismo (Brasil, 2000, 2011), desde o ano de 2000 Florianópolis recebia $18,69 \%$ do total de turistas estrangeiros que visitaram o país e, em 2010, esse índice foi de 19,3\%. Além disso, a cidade tem sido manchete em jornais nacionais e internacionais como principal destino turístico e com alta qualidade de vida. Recentemente o The New York Times (2011) destacou as oportunidades de negócios que existem no mercado imobiliário e turístico na ilha com a chamada "Local property values on Florianopolis have increased 8 percent to 10 percent during the last five years", ressaltando características como as belezas naturais, tranquilidade, baixo índice de criminalidade, desenvolvimento econômico e crescente valorização imobiliária. Segundo Nick Foster (2011) "the narrow, hilly island is a fixture in quality-of-life surveys in the Brazilian media and this - coupled with strict zoning regulations to protect the island's native forest, sand dunes and lagoons (...)".

Figura 1

Imagem da área central em 1938

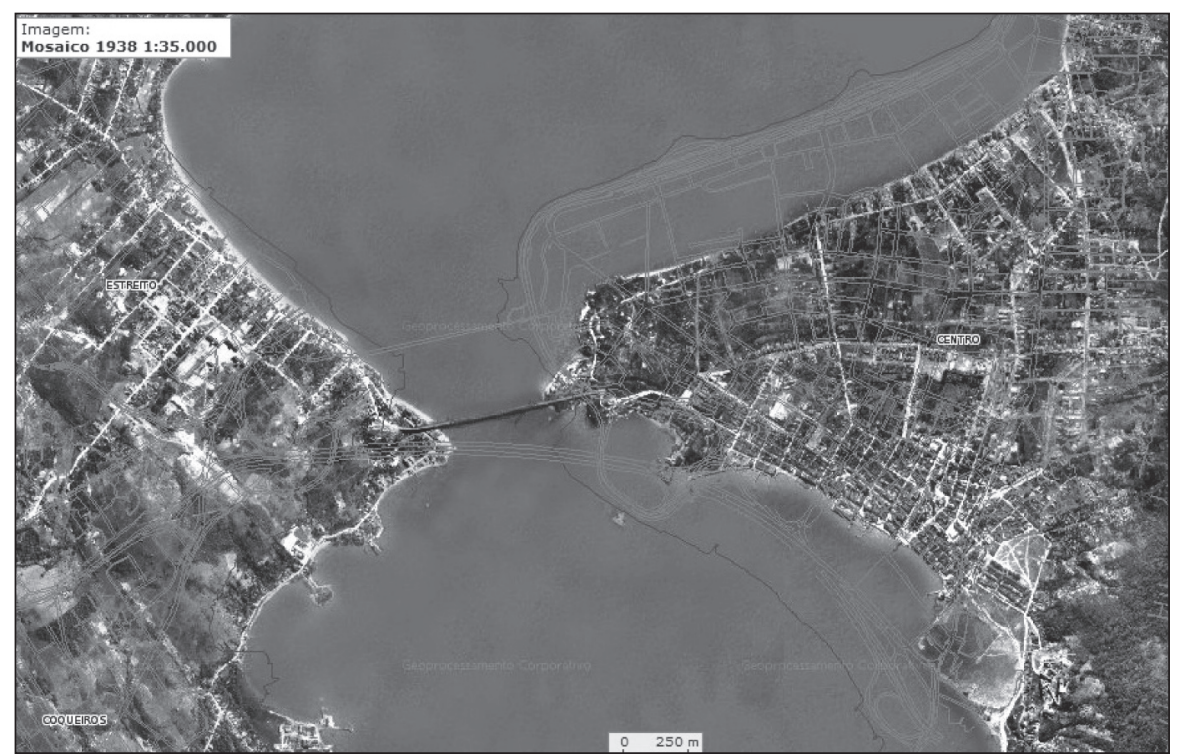

Fonte: Ipuf (2011). 
Figura 2

Imagem da área central em 1994

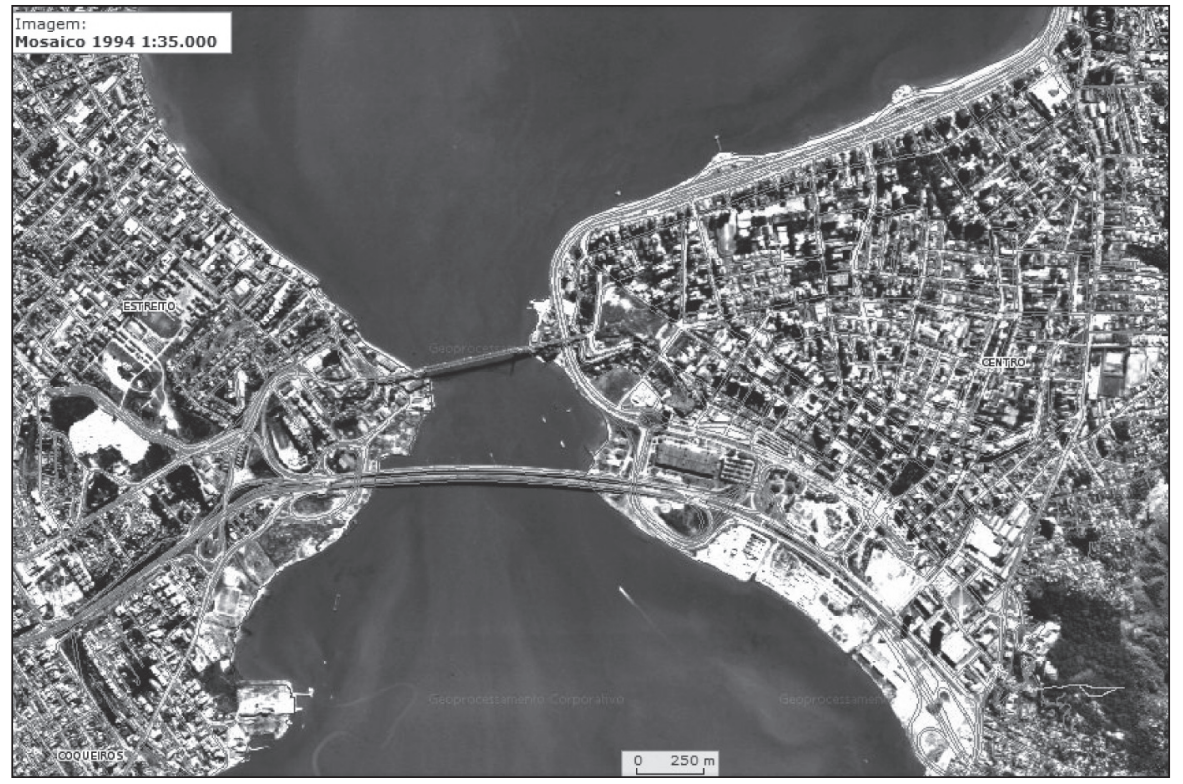

Fonte: Ipuf (2011), adaptada pelos autores.

É interessante observar que Florianópolis não apenas é objeto de reportagens em jornais e telejornais internacionais de referência, mas as reportagens chegam a oferecer detalhes sobre alguns empreendimentos que consideram de alto status, detalhando, inclusive, a área total construída, descrição e valores de imóveis e até mesmo nome de imobiliárias. Em 2009 o NYT já havia eleito Florianópolis como um dos melhores destinos turísticos da América Latina. A BBC News de Londres em 2011 descreveu Florianópolis como uma das 10 cidades mais dinâmicas do mundo, comparando suas belezas e atrativos a de lugares como Havaí nos Estados Unidos, Ibiza na Espanha e Saint Tropez na França. Entretanto, todas as notícias omitem problemas relacionados a transporte público, saneamento, criminalidade e favelas. Tais publicações contribuem para reiterar uma imagem da cidade que tem sido amplamente divulgada nos últimos anos e que repercute diretamente no setor imobiliário em Florianópolis. A imagem de uma cidade tranquila, com qualidade de vida, belezas naturais, livre de problemas é recorrente e faz parte de uma estratégia de city marketing. Souza (2003:302) afirma que o city marketing é "um instrumento de planejamento e gestão urbana na maioria das vezes utilizado para se construir uma imagem 'asséptica' e certinha da cidade em questão, com o fito de atrair investimentos e turistas".

De acordo com a pesquisa sobre que maneira as inserções sociais influenciaram no crescimento do mercado imobiliário em Florianópolis, foi verificado que as primeiras intervenções que contribuíram para o crescimento do setor imobiliário em Florianópolis iniciaram na 
década de 1920 e foram inserções do tipo estruturais - com a construção da primeira ponte (figura 1), a Hercílio Luz, que liga a ilha à parte continental e ao restante do estado de Santa Catarina - iniciando um período de fortes transformações econômicas e sociais na cidade (Campos, 2004).

A partir dessa data, uma sucessão de eventos, investimentos e fatores determinaram o desenvolvimento e expansão da cidade, tais como (Baldança, 2011): a) Fundação do Instituto Estadual de Educação em 1922 (figura 2, item 1); b) Anexação da área continental ao município de Florianópolis em 1944 (figura 2, item 3); c) Inauguração de um terminal de aviação civil para passageiros (Aeroporto Hercílio Luz) em 1955; d) Fundação da Universidade Federal de Santa Catarina em 1960 e da Universidade do Estado de Santa Catarina em 1964; e) Instalação da empresa Eletrosul em 1968; e f) Aterro da Baía Sul durante o Governo Colombo Salles (1972-1975) (figura 2, item 4). O que leva esta pesquisa considerar que entre as décadas de 1920 e 1960 ocorreu uma forte intervenção do estado com investimentos e obras, que se configuram como inserções do tipo políticas, estruturais e culturais que irão resultar na valorização de determinadas áreas da cidade, das quais o mercado imobiliário se apropriara nas décadas seguintes.

A partir da década de 1970 - com a construção da BR-101, da BR-470 e da BR-116 que ligam a capital às regiões Sul-Sudeste do país e ao planalto catarinense, bem como a construção da segunda ponte, a Colombo Sales, em 1975 (figura 2, item 6) - Florianópolis passou a se integrar com a economia regional e nacional e ganhar novo dinamismo nesse campo (Campos, 2004). Ainda na década de 1970, pode-se observar outras inserções que influenciaram no desenvolvimento de núcleos urbanos com dinâmicas diferentes de uso e ocupação do solo, imobiliária e turística: a) Primeira etapa do aterro da avenida Beira-Mar Norte do centro até o bairro da Agronômica (figura 2, item 5); b) Construção da rodovia SC-401 que liga a área central ao norte da ilha; c) Instalação de empresas estatais na região do Itacorubi como a Telesc - que se configuram como inserções.

As obras e instalações na área central e nos bairros situados na bacia hidrográfica do Itacorubi, que se localiza nas proximidades das Universidades Federal e Estadual de Santa Catarina, aliadas à instalação de empresas estatais, foram as principais responsáveis pelo crescimento da região após a década de 1970. Da mesma forma, a construção da rodovia SC-401 impulsionou o desenvolvimento do norte do município. De acordo com Monteiro (2008), nesse período o turismo era incipiente e ocasional, já que a cidade ainda não tomara consciência dessa "vocação", embora já atraísse veranistas do Rio Grande do Sul e do Paraná. O autor faz referência ao desenvolvimento da área compreendida pela Beira-Mar Norte: “(...) Aquilo que era um fundo de quintal de residências, dera lugar a um paredão de edifícios de apartamentos residenciais, acompanhados de franja de bares e restaurantes que incluíram a orla no circuito de lazer noturno da cidade" (Monteiro, 2008:19).

Com a pesquisa foi constatado que alguns dos lugares mais valorizados da área estudada - como a avenida Beira-Mar Norte e o bairro João Paulo - estão dotados predominantemente de inserções estruturais e ambientais - onde estão localizados empreendimentos residenciais de alto padrão que possuem como fator valorizante o relevo em declive e/ou 
belas paisagens com frente para o mar. Há que se mencionar, ainda, que durante a década de 1960 a capital de Santa Catarina recebeu uma grande leva de funcionários públicos em função da instalação da UFSC e de empresas estatais como a Eletrosul. Já durante o início dos anos 1980, o mercado imobiliário da cidade sofreu uma desaceleração em função dos problemas econômicos enfrentados pelo Brasil, durante a segunda crise do petróleo. Foi durante este período que o turismo se tornou uma das atividades mais visadas e estimuladas e impulsionou novamente o desenvolvimento do setor imobiliário e, consequentemente, da construção civil. Esse foi um período de intensa urbanização na área central de Florianópolis.

O desenvolvimento do turismo local fez com que muitos visitantes comprassem terrenos e propriedades nos balneários da cidade, o que criou um novo fôlego para as empreiteiras. O surgimento de condomínios de alto padrão que atendem aos novos residentes próximo dos balneários fez com que boa parte dos habitantes tradicionais mais uma vez fossem deslocados para subúrbios e favelas da cidade. Embora os impactos ambientais e econômicos sejam facilmente perceptíveis na atualidade, grandes empreendimentos continuam sendo realizados com a conivência do poder público. Um exemplo disso é o bairro Santa Mônica, que fora construído sobre um manguezal, onde se localiza um grande shopping, e enfrenta problemas de mobilidade e saneamento básico.

Concomitantemente ao aumento populacional e aos investimentos em infraestrutura, é possível observar um crescimento significativo nos índices na liberação para construção em Florianópolis. De acordo com o Sindicato da Indústria da Construção Civil de Florianópolis (Sinduscon, 2011), a área total autorizada para construção em 1990 foi de $383.676,72 \mathrm{~m}^{2}$. Esse índice aumentou em 54\% no ano de 2000 e 157\% em 2010, alcançando o patamar de 987.935,74 $\mathrm{m}^{2}$ de área a ser construída liberada por meio de 886 alvarás de construção concedidos pela Prefeitura Municipal. No ano 2000, o norte da ilha foi a região que mais adquiriu alvarás de construção, sendo liderada pelo bairro de Canasvieiras, 172 alvarás, totalizando 99.459,71 m² de área construída. Em 2010 os bairros de Ingleses, Centro e Itacorubi foram as regiões em que ocorreu maior número de liberações para construção na ilha. Ainda de acordo com esses dados, o bairro João Paulo no ano de 2003 obteve um alto índice de alvarás de construção em relação ao ano anterior; foram 460\% a mais de área liberada para construção em metros quadrados no ano de 2003 em relação a 2002; enquanto em 2004 esse índice caiu $97 \%$ em relação a 2003. Enquanto na Trindade o maior número de alvarás foi concedido em 2004 e 2006; no Itacorubi, em 2003 e 2008; no Centro, em 1998, 2006, 2009 e 2010; em Ingleses, 1993, 2006, 2008, 2010; em Canasvieiras, em 1994, 2004, 2009; e no Campeche, localizado no sul da ilha - local onde ocorreram poucos investimentos em infraestrutura —, foi a partir de 2008 que se registrou o maior número de área liberada para construção (Sinduscon, 2011). O aumento no número de liberações para construção, além de se caracterizar como uma forte inserção do tipo política, mostra o crescimento do setor imobiliário, sobretudo, na área pesquisada.

As décadas de 1990 e anos 2000 foram marcados por diversas alterações no Plano Diretor de Florianópolis, a maioria relacionada a mudanças nos parâmetros urbanísticos de construção e uso e ocupação do solo (zoneamento), além da criação do Plano Diretor dos bal- 
neários — o que determinou a expansão do mercado imobiliário em áreas específicas do município pela ampliação do potencial construtivo. No início dos anos 2000 foi feita alteração no índice de uso e ocupação do solo no bairro João Paulo, permitindo a construção de edifícios residenciais multifamiliares, o que resultou na liberação de 105.499,43 $\mathrm{m}^{2}$ somente no ano de 2003 (Sinduscon, 2011). Esse período foi fortemente marcado por inserções do tipo política, acompanhada de estruturais e culturais, atendendo às novas necessidades do mercado imobiliário e, ao mesmo tempo, influenciando na valorização dos imóveis.

O aumento significativo da densidade demográfica em Florianópolis é outro aspecto que merece atenção e revela a verticalização na área. Em 2010 se registrou o índice de 627,2 hab/ $\mathrm{km}^{2}$ (IBGE, 2010), enquanto a recomendação da Associação Norte-Americana de Saúde Pública, para que se tenha melhor qualidade de vida e ambiental, é de $32 \mathrm{hab} / \mathrm{km}^{2}$ (Tuan, 1977 apud Nucci, 2008). A verticalização das cidades é uma das teses sobre o aumento da densidade demográfica desordenada e, consequentemente, de queda na qualidade ambiental, que gera problemas individuais e coletivos (Nucci, 2008).

A intensificação do movimento de verticalização da ilha pode ser observada a partir da década de 1970, principalmente na área central, continental e norte da ilha. Os problemas originários desse fenômeno são os mais variados, conforme aponta Nucci (2008), e podem ser identificados em Florianópolis, tais como: congestionamentos, escassez de espaços para lazer, de infraestrutura, impermeabilização do solo, formação de ilhas de calor e degradação ambiental. Essas variáveis podem se configurar como inserções negativas para o setor imobiliário em determinadas áreas da cidade, implicando desvalorização imobiliária, assim como para os empreendimentos que se situam próximos a cemitérios, manguezais, aterros sanitários ou estação de transbordo de resíduos sólidos, como há no Itacorubi.

O crescimento do setor imobiliário em Florianópolis ainda pode ser confirmado pelo aumento de 19,4\% no número de construtoras estabelecidas entre o período 2006-08, pelo aumento de 39,1\% no número de comércio varejista de materiais de construção e pelo aumento de 20,5\% no índice de empregos gerados no ramo da construção (Sebrae, 2010). A arrecadação municipal do Imposto Predial Territorial Urbano (IPTU) entre 2000-07 praticamente duplicou, passando de 47 para 92 milhões de reais (TCE/SC, 2011).

O crescimento urbano e imobiliário em Florianópolis está diretamente ligado às diferentes inserções sociais que vêm ocorrendo desde a década de 1920 e que se intensificaram a partir dos anos 1980 - sendo caracterizadas por elementos estruturais, sociais, culturais e cognitivos. Tais inserções não ocorreram ou não se fazem presentes na mesma intensidade em todo o território municipal, de forma que determinadas áreas são mais valorizadas ou simplesmente desprezadas pelo mercado imobiliário.

Nessa linha, Correa (2000) apresenta e fala sobre a atuação dos agentes sociais que produzem o espaço urbano: proprietários dos meios de produção, proprietários fundiários, promotores imobiliários, estado e grupos sociais excluídos. Os promotores imobiliários, por exemplo, são grupos que realizam - parcial ou totalmente - atividades de incorporação, financiamento, construção, produção ou comercialização de imóveis e estes procuram produzir imóveis de alto padrão e status em áreas nobres onde o preço da terra costuma ser elevado, 
ou seja, onde há maior acessibilidade, eficiência e segurança dos meios de transporte e amenidades naturais. E são estas características que "em conjunto tendem a valorizar diferencialmente certas áreas da cidade, que se tornam alvo da ação maciça dos promotores imobiliários (...)" (Correa, 2000:23). Para Correa (2000), na sociedade capitalista não há interesse desses agentes em produzir imóveis para as classes mais populares.

A partir dos dados sobre o setor imobiliário em Florianópolis, a pesquisa, nesta etapa, analisa as diferentes áreas da cidade a partir das quatro inserções de Zukin e DiMaggio (1990) e Fligstein (2001) - política, estrutural, cultural e cognitiva - conforme quadros 1 e 2.

Quadro 3

Inserções sociais por núcleos e regiões geográficas, Florianópolis (SC)

\begin{tabular}{|c|c|c|c|c|}
\hline Núcleos & $\begin{array}{l}\text { Região } \\
\text { geográfica }\end{array}$ & $\begin{array}{c}\text { Área no } \\
\text { mapa } \\
\text { (figura 3) }\end{array}$ & Bairros & $\begin{array}{l}\text { Inserções sociais } \\
\text { predominantes }\end{array}$ \\
\hline Distrito Sede & Oeste & 1 & Parte insular - Centro & político/estrutural/ambiental \\
\hline Distrito Sede & Oeste & 2 & $\begin{array}{c}\text { Parte continental - Estreito, } \\
\text { Coqueiros }\end{array}$ & político/estrutural \\
\hline Distrito Sede & Oeste & 3 & $\begin{array}{l}\text { Bacia do Itacorubi - Trindade, } \\
\text { Itacorubi, Santa Mônica }\end{array}$ & cultural/cognitivo \\
\hline Distrito Sede & Oeste & 4 & $\begin{array}{c}\text { Bacia do Saco Grande - João } \\
\text { Paulo, Cacupé }\end{array}$ & político \\
\hline $\begin{array}{l}\text { Distrito do Ribeirão da } \\
\text { Ilha }\end{array}$ & Sudoeste & 5 & Região do Aeroporto - Carianos & estrutural/cultural \\
\hline Distrito de Canasvierias & Noroeste & 6 & Jurerê, Daniela, Jurerê Internacional & cognitivo/estrutural \\
\hline Distrito de Canasvieiras & Norte & 7 & Canasvieiras & estrutural/cultural \\
\hline $\begin{array}{l}\text { Distrito Ingleses do Rio } \\
\text { Vermelho }\end{array}$ & Nordeste & 8 & Ingleses, Santinho & político/cultural \\
\hline $\begin{array}{l}\text { Distrito da Lagoa da } \\
\text { Conceição }\end{array}$ & Leste & 9 & Lagoa da Conceição, Praia Mole & cognitivo/cultural/ambiental \\
\hline Distrito do Campeche & Sudeste & 10 & Campeche, Novo Campeche & político/estrutural/ambiental \\
\hline
\end{tabular}

Fonte: Elaborado pelos autores com base na pesquisa realizada.

Com base nos dados levantados e no quadro acima é possível perceber que as inserções que influenciaram o crescimento da área central e das bacias do Itacorubi e Saco Grande (áreas 1, 2, 3 e 4) estão ligadas a alterações na lei de disciplina, parcelamento, uso e ocupação do solo; construção das pontes, aterros, avenidas e estruturas públicas administrativas e/ou educacionais - que se caracterizam por inserções políticas e estruturais. 
Figura 3

Mapa dos distritos administrativos de Florianópolis e áreas pesquisadas pelas inserções e ação do mercado imobiliário

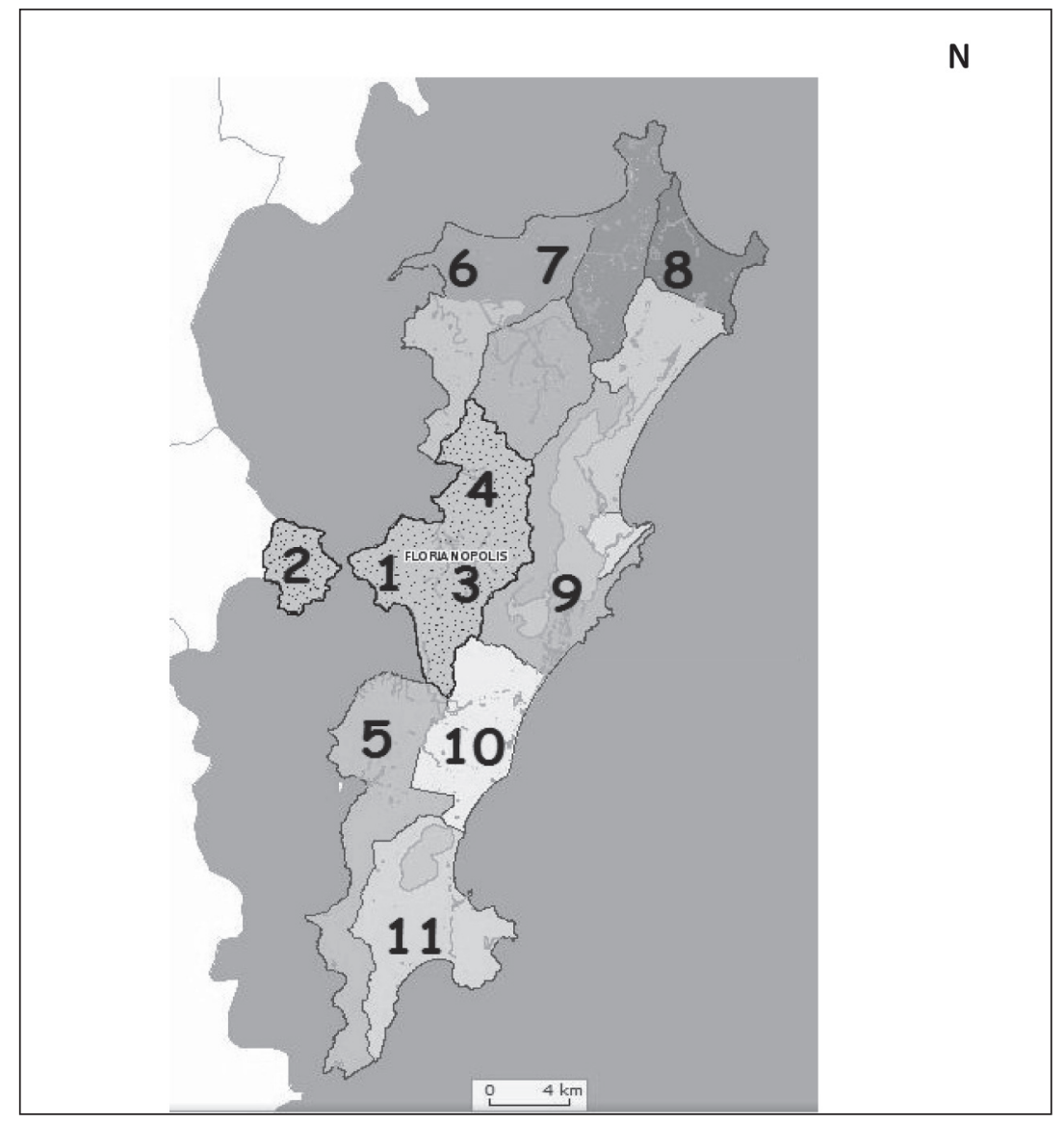

Fonte: Ipuf (2011) adaptado pelos autores.

Já no Norte/Nororeste (áreas 6, 7 e 8) — além de alterações na lei de disciplina, parcelamento, uso e ocupação do solo, da implementação de bons acessos e construção de rodovias —, o fator ambiental foi bastante relevante para o crescimento e valorização imobiliária na região, já que esta possui belas paisagens naturais, amenidades físicas e conta com baías de águas calmas. No distrito 5 (figura 3) — onde situam-se Canasvieiras, Jurerê, Daniela, Jurerê Internacional - está localizada uma Unidade de Conservação Federal composta principalmente por manguezais - área rica em recursos naturais, sobretudo, hídricos. Jurerê Internacional, por exemplo, conta com sistema próprio e privado de abastecimento de água e tratamento de esgoto, forte atuação de empresas de segurança privada e junto com Canasvieiras é um dos destinos mais procurados da ilha por turistas, também pela oferta de serviços ligados 
a festas, bares, restaurantes. Nesse distrito as inserções estrutural, cultural e cognitiva são as mais consideráveis nessas áreas.

Na região Leste, onde situa-se a Lagoa da Conceição (área 9), as paisagens naturais, amenidades físicas e a própria lagoa são as responsáveis pelo crescimento do setor imobiliário, voltado para a produção de residências unifamiliares e, posteriormente, o desenvolvimento do setor de serviços (bares, restaurantes, cafés, casas noturnas), além da prática de esportes aquáticos - o que caracteriza a predominância das inserções cognitiva e cultural.

Por fim, as áreas pesquisadas no sul da ilha, destacam-se as influências das inserções estrutural e cultural no caso da área 5 — onde se localiza o Aeroporto Internacional Hercílio Luz —, com a predominância de bairros residenciais unifamiliares. E no Campeche, área 10, predominam as inserções político e estrutural, observadas, principalmente, pelas alterações na lei de disciplina, parcelamento, uso e ocupação do solo e pela implementação de melhores acessos em relação aos demais bairros localizados no sul da ilha.

Observando o processo de urbanização e a dinâmica do mercado imobiliário, concluímos ao longo desta pesquisa que o distrito sede possui quatro dinâmicas diferentes de desenvolvimento. Por tal motivo este foi eleito para a segunda etapa da pesquisa: a) Área central (insular); b) Área continental; c) Bacia hidrográfica do Itacorubi; d) Bacia hidrográfica do Saco Grande. Tais áreas, supostamente, apresentam diferentes perfis de consumidores no mercado imobiliário e, consequentemente, diferentes valores por metro quadrado.

Nas áreas que apresentam maior valor pode-se verificar a concentração de imóveis de alto status e verticalização da área — pela falta de espaço para expansão — , bem como forte intervenção do estado para sua estruturação com obras, investimentos e alterações na legislação. A citação de Smith (1983) sobre o mérito dos metais preciosos — ao afirmar que "sua beleza é realçada pela sua escassez" e que por tal motivo se torna objeto de desejo, em que os "ricos" estão dispostos a pagar um preço mais alto, o que faz com que seu preço seja elevado - é uma boa metáfora para aludir à área central e ao bairro João Paulo, que, além de inserções estruturais, apresentam inserções políticas, culturais, ambientais e cognitivas, que colaboram para a alta valorização imobiliária.

Recentemente, a Fundação Instituto de Pesquisas Econômicas de São Paulo realizou um levantamento sobre o mercado imobiliário em 40 cidades brasileiras, mais o Distrito Federal - entre as quais, Florianópolis. A pesquisa revelou que na área correspondente ao distrito sede existem quatro diferentes faixas de preço médio por metro quadrado. As áreas com menor valor situam-se na área continental e na bacia hidrográfica do Saco Grande, variando entre R\$ 2.800 e R \$ 4.000 o metro quadrado; enquanto as áreas com maior valor situam-se na área central (insular), na bacia do Itacorubi e no bairro João Paulo, variando entre $\mathrm{R} \$ 4.000$ e R\$ 6.000 o metro quadrado. Observando o valor apresentado pela Fipesp em análise ao preço do mercado imobiliário de Florianópolis, pode-se concluir que as quatro faixas de preço médio apresentadas equivalem à divisão adotada por esta pesquisa para caracterizar o distrito sede. Ainda, pode-se verificar que os maiores preços estão na área central e bacia hidrográfica do Itacorubi - áreas onde se verifica maior número de inserções políticas, estruturais, culturais e cognitivas —, sobretudo ambientais — que contribuem na valorização dos imóveis. Já a 
área continental e bacia hidrográfica do Saco Grande apresentam sucessivamente os menores preços da área de estudo, de acordo com o Fipesp, e o menor número de inserções sociais verificadas pela pesquisa no Distrito Sede.

\section{Considerações finais}

O setor imobiliário de Florianópolis é dinâmico. Em que pese haver várias questões que podem remeter a novos questionamentos, nota-se que as inserções evidenciam novas configurações sociais em termos de localização imobiliária, que decorrem de uma variedade de aspectos socioeconômicos.

Se a gestão urbana, como um fato social, estiver focada como apenas uma das áreas do conhecimento humano, a exemplo da economia, corre-se o risco de não se compreender a complexidade do campo de forma adequada. Isto porque esse campo sofre várias inserções sociais, às quais, como uma via de mão dupla, dialeticamente, influenciam e são influenciadas por aquilo que se considera o essencial econômico. Este estudo desenvolveu sua análise tendo como objeto as inserções; elas foram as variáveis, e não os fatores subjetivos dos membros da comunidade analisada. Em outras palavras, partiu-se do postulado de que as inserções sociais são expressões de subjetividades. Novamente, aqui, a dialética.

Neste contexto social, a estrutura, a política, a cultura, o conhecimento e o meio ambiente são fatores que circulam, interagem e constituem a ordem econômica. Esta é a principal constatação que se busca comprovar pela presente pesquisa no setor imobiliário de Florianópolis. Os procedimentos metodológicos adotados encaminham para os fatos que permitem esta constatação. A análise histórica da trajetória deste importante setor da economia da capital de Santa Catarina, particularmente do distrito sede de Florianópolis, permite vincular diversas etapas, desde o seu início, crescimento, períodos de esplendor e crises, ao que se denomina de inserções sociais.

A partir da década de 1960, a ordem política dotou as cidades de importantes obras de infraestrutura, o que alicerçou um boom na construção civil. Isso contribuiu para que nesta fase se consolidassem novos valores culturais - de lazer, consumo, espetáculos, busca de status etc. - professados por importantes setores sociais. Para entender esse processo devese considerar que Florianópolis foi alvo de busca de turismo, trabalho e local de residência de muitas pessoas oriundas de interior de Santa Catarina, de outros estados brasileiros e até do exterior, principalmente a partir de 1970. Contribuiu também essencialmente para este período de crescimento a incorporação de novos conhecimentos em vários campos da ciência, desde saúde e medicina, passando pela física, química, arquitetura e engenharia, até pela administração pública, empresarial e pela economia.

Uma terceira etapa da trajetória do setor imobiliário de Florianópolis pressupõe-se esteja sendo edificada: o crescimento sustentável. Este crescimento continua tendo vínculos fortes com a inserção estrutural existente e possível de ser mantida. Tem vínculos com a ordem política democrática de Florianópolis - com mobilizações sociais contra a corrupção, por 
mais participação de diversos conselhos comunitários. O crescimento sustentável também está vinculado à cultura virtual, mais democrática e mais horizontalizada, presente nas redes sociais. O modelo sustentável depende igualmente de novos conhecimentos científicos cada vez mais difundidos. A ciência ambiental encontra sintonia em movimentos ecologistas e produz uma nova consciência social sobre a necessidade da preservação e da recuperação do meio ambiente como condição para a sobrevivência das cidades.

Os quadros produzidos nesta pesquisa permitem uma classificação e uma discriminação do distrito sede - área Central, Trindade, Itacorubi e Saco Grande - de Florianópolis. Esta nova visualização possibilita a classificação por períodos históricos, por áreas, por empreendimentos na infraestrutura, por alterações do Plano Diretor, por decisões judiciais, pela incorporação de novos conhecimentos e pela compreensão da importância do setor ambiental. Em Florianópolis a questão ambiental tem sido objeto de ações judiciais, de denúncias, de embargos, de manifestações sociais, de ações de ONGs etc., o que não é exclusivo desta cidade. O fato é que o meio ambiente torna-se, cada vez mais, um fato político e, por essa razão, adotouse, neste estudo, o meio ambiente como uma quinta inserção social: a inserção ambiental.

Para além das discussões possíveis a partir deste estudo, observa-se que a NSE é um campo teórico adequado para análises sociais complexas, como a do setor imobiliário.

\section{Referências}

ARMSTRONG, D. et al. The place of inter-rater reliability in qualitative research: an empirical study. Sociology, v. 31, n. 3, p. 597-606, Aug. 1997.

AUDI, Robert. Dicionário de filosofia de Cambridge. São Paulo: Paulus, 2006.

BALDANÇA, Luciano G. Arquiteto urbanista. Principais obras e instalações que possibilitaram o crescimento de Florianópolis. Entrevista realizada por Deisiane Delfino. 12 out. 2011.

BBC. Brazilian city flourishes in financial crisis. 10 maio 2011. Disponível em: < http://news.bbc. co.uk/2/hi/programmes/fast_track/9480739.stm>. Acesso em: $1^{\circ}$ nov. 2011.

BOBBIO, Norberto; MATTEUCI, Nicolas; PASQUINO, Gianfranco. Dicionário de política. 12. ed. Brasília: UnB, 2000.

BOURDIEU, Pierre. Le champ économique. Actes de la Recherche en Sciences Sociales, n. 119, p. 48-66, 1997.

BRASIL. Ministério do Turismo. Estudo de demanda turística internacional. Brasília, 2000. Disponível em: <www.dadosefatos.turismo.gov.br/export/sites/default/dadosefatos/demanda_turistica/ internacional/download_internacional/EstudodaDemandaInternacional2000.pdf $>$. Acesso em: 4 nov. 2011.

BRASIL. Ministério do Turismo. Estudo de demanda turística internacional. Brasília, 2011. Disponível em: <www.dadosefatos.turismo.gov.br/export/sites/default/dadosefatos/demanda_turistica/inter- 
nacional/download_internacional/Demanda_Turxstica_Internacional_-_Fichas_Sinteses_-_20042010.pdf>. Acesso em: 4 nov. 2011.

BRAUDEL, Fernand. Civilização material, economia e capitalismo: séculos XV-XVIII. São Paulo: Martins Fontes, 1998. v. 2.

BUGLIONE, Samantha. Direito, ética e bioética. Fragmentos do cotidiano. Rio de Janeiro: Lumen Juris, 2010.

CAMPOS, Edsom T. A expansão imobiliária e seus impactos ambientais em Florianópolis. Florianópolis: Insular, 2004.

COCHOY, Franck. Une petite histoire du client, ou la progressive normalisation du marché et de l'organization. Sociologie du Travail, v. 44, n. 2, p. 357-380, 2002.

CORREA, Roberto. O espaço urbano. São Paulo: Ática, 2000.

CUNHA, Antonio Geraldo da. Dicionário etimológico Nova Fronteira da língua portuguesa. 2. ed. Rio de Janeiro: Nova Fronteira, 2000.

DC. Diário Catarinense. Santa Catarina se consolida como terceiro principal destino turístico do Brasil. Disponível em: <www.clicrbs.com.br/diariocatarinense/jsp/default.jsp?uf=2\&local=18\&newsID $=$ a3535206.xml\&channel $=67 \&$ tipo $=1 \&$ section $=$ Geral, publicado em 21/10/2011 > . Acesso em: $1^{\circ}$ nov. 2011.

DC. Diário Catarinense. Turismo e especulação imobiliária em Florianópolis são destaque no New York Times. 8 jul. 2011. Disponível em: <www.clicrbs.com.br/diariocatarinense/jsp/default.jsp?uf=2\& local $=18 \&$ section $=$ Geral\&newsID $=$ a3381112.xml $>$. Acesso em: $1^{\circ}$ nov. 2011.

DURKHEIM, Émile. De la division du travail social. Paris: PUF, 1893.

FLIGSTEIN, Neil. Mercado como política: uma abordagem político-cultural das instituições de mercado. Contemporaneidade e Educação, ano VI, n. 9, p. 26-55, $1^{\circ}$ set. 2001

FOSTER, Nick. On an Island in Brazil, a Real Estate Boom Lingers. The New York Times. 7 jul. 2011. Disponível em: <www.nytimes.com/2011/07/08/greathomesanddestinations/08iht-reflorian08. html>. Acesso em: $1^{\circ}$ nov. 2011.

FUSFELD, Daniel R. A era do economista. São Paulo: Saraiva, 2003.

GRANOVETTER, Mark S. Ação econômica e estrutura social: o problema de incrustação. In: MARQUES, R.; PEIXOTO, J. (Org.). A nova sociologia econômica: uma antologia. Oeiras: Celta Editora, 2003. p. 69-102.

GRANOVETTER, Mark S. Economic action and social structure: the problem of embeddedness. American Journal of Sociology, n. 91, p. 481-510, 1985.

HOBBES, Thomas. Os pensadores. São Paulo: Nova Cultural, 1997.

IBGE. Instituto Brasileiro de Geografia e Estatística. Censo demográfico. 1970, 1980, 1991, 2000, 2010. 
IPUF. Instituto de Planejamento Urbano de Florianópolis. Florianópolis: dinâmica demográfica e projeção da população por sexo, grupos etários, distritos e bairros (1950-2050). Florianópolis: Ipuf, 2007.

IPUF. Instituto de Planejamento Urbano de Florianópolis. Geoprocessamento corporativo. Disponível em: <www.pmf.sc.gov.br/entidades/ipuf/>. Acesso em: 4 nov. 2011.

MINAYO, Maria C. de S. O desafio do conhecimento. São Paulo; Rio de Janeiro: Hucitec-Abrasco, 1994.

MINELLA, Ary César et al. Apresentação do Dossiê Estado, Mercado, Regulação. Revista Política \& Sociedade, n. 6, abr. 2005.

MONTEIRO, Carlos A. de F. Florianópolis: o direito e o avesso. In: NUCCI, João Carlos. Qualidade ambiental e adensamento urbano. Um estudo da ecologia e planejamento da paisagem aplicado ao distrito de Santa Cecília (MSP). 2. ed. Curitiba: O Autor, 2008. p. 14-37.

PARETO, Vilfredo. Manuel d'économie politique. Genebra: Droz, 1981 [1909].

PINHEIRO FILHO, Fernando. A noção de representação em Durkheim. Lua Nova: Revista de Cultura e Política, São Paulo, n. 61, 2004. Disponível em: <http://dx.doi.org/10.1590/S010264452004000100008>. Acesso em: 24 jan. 2013.

PNUD. Programa das Nações Unidas para o Desenvolvimento. Índice de desenvolvimento humano — municipal, 1991 e 2000. Disponível em: <www.pnud.org.br/atlas/ranking/IDH-M\%2091\%20 00\%20Ranking\%20decrescente\%20(pelos\%20dados\%20de\%202000).htm>. Acesso em: $1^{\circ}$ nov. 2011.

POLANYI, Karl. A grande transformação: as origens de nossa época. 2. ed. Rio de Janeiro: Campus, 2000.

RICARDO, David. Princípios de economia política e tributação. São Paulo: Abril, 1988.

RODRIGUES, José A. (Org.). Durkheim. Ática: São Paulo, 1984.

SANTA CATARINA. Tribunal de Contas. Contas anuais dos municípios. Florianópolis. Disponível em: <http://www.tce.sc.gov.br/web/contas/municipal>. Acesso em: 5 nov. 2011.

SEBRAE/SC. Santa Catarina em números. Florianópolis: Sebrae/SC, 2010.

SINDUSCON. Sindicato da Indústria da Construção Civil de Florianópolis. Área total liberada por dados de alvarás de construção concedidos pela Prefeitura de Florianópolis. Disponível em: <www. sinduscon-fpolis.org.br/>. Acesso em: 4 nov. 2011.

SMITH, Adam. Riqueza das nações. São Paulo: Abril, 1983. v. I.

SOUZA, Marcelo Lopes de. Mudar a cidade: uma introdução crítica ao planejamento e à gestão urbanos. 2. ed. Rio de Janeiro: Bertrand Brasil, 2003.

SPANIOL, Enio Luiz. A conflitividade na relação do Estado, mercado e sociedade: estudo hemerográfico. Tese (doutorado em sociologia política) - Universidade Federal de Santa Catarina, Florianópolis, 2009. 
STEINER, Philippe. A sociologia econômica. São Paulo: Atlas, 2006.

THE NEW YORK TIMES. The place to be: Florianópolis, Brazil. 8 jan. 2009. Disponível em: <http:// news.bbc.co.uk/2/hi/programmes/fast_track/9480739.stm>. Acesso em: $1^{\circ}$ nov. 2011.

TUAN, Yi-Fu. Espaço e lugar. A perspectiva da experiência. São Paulo: Difel, 1977.

WEBER, Max. Économie et société. Paris: Plon, 1970 [1921].

ZUKIN, Sharon; DIMAGGIO, Paul. Introduction. In: ZUKIN, Sharon; DIMAGGIO, Paul. Structures of capital. The social organization of the economy. Cambridge: Cambridge University Press, 1990. p. 1-36.

Enio Luiz Spaniol é doutor em sociologia e professor da Faculdade de Administração Pública da Esag, da Universidade do Estado de Santa Catarina (Udesc). E-mail: elspnl@yahoo.com.br.

Ivoneti Ramos é mestre em economia e professora da Faculdade de Administração Pública da Esag, da Universidade do Estado de Santa Catarina (Udesc). E-mail: ivoneti.ramos@udesc.br.

Samantha Buglione é doutora em ciências humanas, mestre em direito e professora da Faculdade de Administração Pública da Esag, da Universidade do Estado de Santa Catarina (Udesc). E-mail: samantha. esag@gmail.com.

Deisiane Delfino é mestre em desenvolvimento regional e urbano, especialista em políticas públicas, doutoranda do programa de pós-graduação em geografia da Universidade Federal de Santa Catarina (UFSC) e professora da Faculdade de Administração Pública da Esag, da Universidade do Estado de Santa Catarina (Udesc). E-mail: deisidelfino@gmail.com.

Maria Eduarda Razzera é economista da Faculdade de Ciências Econômicas da Esag, da Universidade do Estado de Santa Catarina (Udesc).E-mail: m.eduardarazzera@gmail.com. 
